\title{
ESSD Commentary on Dysphagia Management During COVID Pandemia
}

\author{
Antonio Schindler ${ }^{1} \cdot$ Laura W. J. Baijens $^{2,3} \cdot$ Pere Clave $^{4,5} \cdot$ Bjorn Degen $^{6} \cdot$ Stephanie Duchac $^{7} \cdot$ Rainer Dziewas $^{8}$. \\ Daniele Farneti ${ }^{9} \cdot$ Shaheen Hamdy $^{10} \cdot$ Emilia Michou $^{11}$. Peter Pokieser ${ }^{12} \cdot$ Renee Speyer $^{13} \cdot$ Margaret Walshe $^{14}$. \\ Eric Verin ${ }^{15} \cdot$ Nathalie Rommel ${ }^{16,17}$
}

Received: 3 June 2020 / Accepted: 23 September 2020 / Published online: 27 October 2020

(c) Springer Science+Business Media, LLC, part of Springer Nature 2020

\begin{abstract}
Since the World Health Organization declared the COVID-19 pandemic a Global Public Health Emergency, experts in swallowing are seeking guidance on service delivery and clinical procedures. The European Society for Swallowing Disorders provides considerations to support experts in swallowing disorders in clinical practice. During the COVID-19 pandemic, assessment and treatment of patients with oropharyngeal dysphagia should be provided, while at the same time balancing risk of oropharyngeal complications with that of infection of patients and healthcare professionals involved in their management. Elective, non-urgent assessment may be temporarily postponed and patients are triaged to decide whether dysphagia assessment is necessary; instrumental assessment of swallowing is performed only if processing of the instruments can be guaranteed and clinical assessment has not provided enough diagnostic information for treatment prescription. Assessment and management of oropharyngeal dysphagia is a high-risk situation as it must be considered an aerosol-generating procedure. Personal protective equipment (PPE) should be used. Telepractice is encouraged and compensatory treatments are recommended.
\end{abstract}

Keywords COVID-19 - Dysphagia - Assessment - Personal protective equipment

Nathalie Rommel

president@essd.org

1 Phoniatric Unit, Department of Biomedical and Clinical Science "L. Sacco", University of Milan, Milan, Italy

2 Department of Otorhinolaryngology, Head and Neck Surgery, Maastricht University Medical Center, Maastricht, The Netherlands

3 GROW-School for Oncology and Developmental Biology, Maastricht University Medical Center,, Maastricht, The Netherlands

4 Gastrointestinal Physiology Laboratory. Hospital de Mataró, Universitat Autònoma de Barcelona, Mataró, Spain

5 Centro de Investigación Biomédica en Red de Enfermedades Hepáticas y Digestivas (CIBERehd), Barcelona, Spain

6 Dysphagiezentrum Wien, Vienna, Austria

7 SRH Hochschule für Gesundheit, University of Applied Health Sciences, Campus Karlsruhe Benzstr. 5, Karlsruhe, Germany

8 Department of Neurology, University Hospital Münster, Albert-Schweitzer-Campus 1, Munster, Germany

9 Audiology Phoniatric Service - ENT Department, Infermi Hospital of Rimini - AUSL Romagna, Rimini, Italy
10 GI Sciences, School of Medical Sciences, Clinical Sciences Building, University of Manchester, Salford Royal Hospital, Salford M6 8HD, UK

11 Department of Speech Language Therapy, School of Rehabilitation Sciences, University of Patras, Patras, Greece

12 Unified Patient Program, Teaching Center, Medical University of Vienna, Vienna, Austria

13 Department Special Needs Education, University of Oslo, Oslo, Norway

14 Department of Clinical Speech and Language Studies, Trinity College Dublin, The University of Dublin, Dublin 2, Ireland

15 Rouen University Hospital, University of Rouen, 3830 Normandy, EA, France

16 Dept of Neurosciences, ExpORL, Deglutology and University Hospital Leuven, University of Leuven, Leuven, Belgium

17 Dept Gastroenterology (Neurogastroenterology and Motility), University of Leuven, Leuven, Belgium 
The World Health Organization (WHO) declared the COVID-19 pandemic a Global Public Health Emergency of international concern [1, 2]. Experts in swallowing disorders (deglutologists, speech and language pathologists, nurses, physiotherapists, occupational therapists and medical doctors of different disciplines including but not restricted to neurology, otorhinolaryngology, phoniatrics, radiology, physical medicine and rehabilitation) are faced with a new situation and are seeking guidance on service delivery and clinical procedures during the COVID-19 pandemic. Several national societies have developed documents to guide clinicians in dysphagia management during the COVID-19 pandemic [3-6].

The European Society for Swallowing Disorders (ESSD) aims to provide considerations based on an evolving body of literature, front-line information from this early stage pandemic and statements from several national and international health care bodies and societies. This commentary has been developed based on the literature available and preliminary clinical experience of European dysphagia clinicians, following discussion among dysphagia experts within the ESSD, taking into account different perspective from different countries. The methodology used reflects a discussive approach across experts in dysphagia, with a consensus through multiple interchanges between the experts and agreed opinion.

As the health care emergency is rapidly evolving and subject to change and new information and data will become available, these considerations may require individualization based on region, facility, resources, and patient-specific factors. Each swallowing expert should adhere to his/her own country, regional and facility regulations.

During the COVID-19 pandemic, assessment and treatment of patients with oropharyngeal dysphagia should be provided, while at the same time balancing risk of oropharyngeal complications (aspiration pneumonia, malnutrition) with that of infection of patients and healthcare professionals involved in their management. Regarding COVID-19 infection status, two categories of patients can be considered:

1. COVID-19-positive patients (COVID+ve), confirmed by positive pharyngeal/nasal swab or chest X-ray/CT scan suggesting interstitial pneumonia, or symptoms of COVID-19 infection (in particular cough, fever, dyspnea, anosmia) and contact with a COVID-19-positive or suspected positive patient;

2. COVID-19-negative patients (COVID-ve), confirmed by negative pharyngeal/nasal swab or asymptomatic without known COVID-19 exposure.
Among swallowing experts, there are many questions on dysphagia management during the COVID-19 pandemic. A few of these questions are addressed below.

(1) When should patients suspected of dysphagia be live assessed?

Elective, non-urgent assessment may be temporarily postponed. Assessment procedures are often restricted to patients who are at significant risk of developing dysphagia-related complications (aspiration pneumonia-sepsis, malnutrition) or in cases of dysphagia of unknown origin and risk of life-threatening underlying disease (such as head and neck cancer or neuromuscular disorders). In the case of patients safely receiving sufficient nutrition (oral or via PEG/NGT), the swallowing assessment procedure may be postponed in most cases.

Both COVID+ve and COVID-ve patients are triaged to decide whether dysphagia assessment is necessary. Information on patient COVID-19 status and risk of dysphagia complications are obtained via remote systems (phone, email, telepractice), and/or through other colleagues, e.g., nurses, but preferably confirmed in writing.

(2) What should be avoided during the assessment of patients suspected of having dysphagia?

In both COVID+ve and COVID-ve patients, assessment procedures aim to estimate the risk of complications. Cough reflex testing, gag testing, voluntary cough, cervical auscultation are avoided in COVID+ve patients.

(3) When should instrumental swallowing assessment be performed?

In deciding when instrumental assessment should be performed, swallowing experts should guarantee that the procedure avoids the following:

(a) COVID-19 infection of the examiner

(b) COVID-19 infection of the patient being examined as well as the incoming patients examined using the same instruments and/or in the same environment [7].

Instrumental assessment of swallowing (Videofluoroscopic Swallow Study, Fiberoptic Endoscopic Evaluation of Swallowing, Manometry) is performed only if appropriate cleaning and processing of the instruments according COVID-19 conditions can be guaranteed [8-10].

In both COVID+ve and COVID-ve patients, instrumental assessment of swallowing (Videofluoroscopic Swallow Study, Fiberoptic Endoscopic Evaluation of Swallowing, Manometry) is performed only if a potential life-threatening 
underlying disease is suspected, clinical assessment has not provided enough diagnostic information for effective treatment to be prescribed to the patients and the clinical situation does not allow the clinical decision to be postponed.

(4) How is the expert in swallowing disorders protected?

Assessment and management of oropharyngeal dysphagia is a high-risk situation as it must be considered an aerosol-generating procedure (AGP) [11-13]. Personal protective equipment (PPE) should be used [14-16].

PPE with COVID-ve patients: the expert in swallowing disorders wears protective eyewear, surgical mask and gloves.

PPE with COVID+ve patients: the expert in swallowing disorders should wear Filtering FacePiece (FFP) 2/3 mask, gloves, protective eyewear, water-proof disposable gowns and disposable hairnet. The swallowing expert should be trained in how to use PPE.

In order to minimize the risk of infection, in addition to the use of PPE, the swallowing expert can use additional precautions, if applicable. During assessment/ management of patients with oropharyngeal dysphagia:

- voluntary cough should be avoided

- less than $1 \mathrm{~m}$ distance from the patients should be avoided as much as possible

- patients are asked to wear a mouth mask, where possible, before and during the procedure; patients' hands should be washed before the procedure

- time devoted to assessment and treatment procedures should be restricted as much as possible.

- How is dysphagia treated during COVID pandemic?

In both COVID+ve and COVID-ve patients, telepractice is encouraged.

In COVID + ve patients:

- compensatory treatments are recommended

- coughing maneuvers (e.g., super-supraglottic swallow) in presence of the swallowing expert should be avoided

- all AGP procedures such as EMST/IMST and thermotactile stimulation should be avoided if directly provided by health personnel.

- patient self oral care should be encouraged, as direct oral care by health care personnel is a high-risk procedure

- in cases where oral feeding is considered unsafe, a NG tube is placed wearing PPE. PEG placement should be considered only if COVID-19 infection to both the patient and the health care personnel is ruled out
- surgical or endoscopic dysphagia treatment (f.i. UES myotomy, esophageal dilation, laryngeal suspension, medialization thyroplasty, laryngeal injections) should be postponed.

\section{Conclusion}

In order to support clinicians in daily practice during COVID-19 pandemic, several guidance documents have been written by bodies of different professions in different areas of the world [3-6, 8, 9, 17-21]. All published documents recommend the use of PPE for live management of dysphagia in COVID+ve patients and encourage compensatory treatments and telepractice. Given the European heterogeneity, this commentary provides a general framework for the front-line clinicians that allow adaptation to professional and local requirements, particularly because differences exist on the prevalence and management of COVID-19 patients among countries and areas. There are also dissimilarities among countries on how to manage patients without symptoms and patients with no previous contact with COVID+ve patients because pre-symptomatic and asymptomatic transmission during assessment and treatment is a potential risk. While in some countries, the latter patients are managed as COVID-ve, in other countries they are considered as potential COVID+ve and managed as such. Country, regional and facility regulations should be followed. Based on the available data and our local experience, we provide in the current commentary some recommendations and best available practical information for test procedures and treatment in dysphagia patients during the COVID-19 pandemic era.

Funding This paper received no specific grant from any funding agency in the public, commercial, or non-profit sectors.

\section{Compliance with Ethical Standards}

Conflict of interest None of the authors have any conflict of interest to disclose or funding to declare in relation to this manuscript.

Ethical Approval This project did not involve research on human participants and/or animals and hence no informed consent was applicable.

\section{References}

1. World Health Organization. Infection prevention and control during health care when COVID-19 is suspected https://www.who. int/publications-detail/infection-prevention-and-control-durin g-health-care-when-novel-coronavirus-(ncov)-infection-is-suspe cted-20200125. 
2. Wang C, Horby PW, Hayden FG, Gao GF. A novel coronavirus outbreak of global health concern. Lancet. 2020;395(10223):470-3.

3. Ku PKM, Holsinger FC, Chan JYK, Yeung ZWC, Chan BYT, Tong MCF, Starmer HM. Management of dysphagia in the patient with head and neck cancer during COVID-19 pandemic: practical strategy. Head Neck. 2020. https://doi.org/10.1002/hed.26224.

4. Zhao C, Viana A Jr, Wang Y, Wei HQ, Yan AH, Capasso R. Otolaryngology during COVID-19: preventive care and precautionary measures. Am J Otolaryngol. 2020. https://doi.org/10.1016/j. amjoto.2020.102508.

5. Mattei A, Amyde la Bretèque B, Crestani S, Crevier-Buchman L, Galant C, Hans S, Julien-Laferrière A, Lagier A, Lobryeau C, Marmouset F, Robert D, Woisard V, Giovanni A. Guidelines of clinical practice for the management of swallowing disorders and recent dysphonia in the context of the COVID-19 pandemic. Eur Ann Otorhinolaryngol Head Neck Dis. 2020. https://doi. org/10.1016/j.anorl.2020.04.011.

6. Lu D, Wang H, Yu R, Yang H, Zhao Y. Integrated infection control strategy to minimize nosocomial infection of coronavirus disease 2019 among ENT healthcare workers. J Hosp Infect. 2020;104(4):454-5. https://doi.org/10.1016/j.jhin.2020.02.018.

7. Lindsley WG, Pearce TA, Hudnall JB, et al. Quantity and size distribution of cough-generated aerosol particles produced by influenza patients during and after illnesses. J Occup Environ Hyg. 2012;9:443-9.

8. Rameau A, Young VN, Amin MR, Sulica L. Flexible laryngoscopy and COVID-19. Otolaryngol Head Neck Surg. 2020. https ://doi.org/10.1177/0194599820921395.

9. De Luca P, Scarpa A, Ralli M, De Vincentiis M, Cassandro E, Chiarella G, Cassandro C. Nasal, pharyngeal and laryngeal endoscopy procedures during COVID-19 pandemic: available recommendations from national and international societies. Eur Arch Otorhinolaryngol. 2020. https://doi.org/10.1007/s00405-02006028-1.

10. Reddy PD, Nguyen SA, Deschler D. Bronchoscopy, laryngoscopy, and esophagoscopy during the COVID-19 pandemic. Head Neck. 2020. https://doi.org/10.1002/hed.26221.

11. Tran K, Cimon K, Severn M, Pessoa-Silva CL, Conly J. Aerosol generating procedures and risk of transmission of acute respiratory infections to healthcare workers: a systematic review. PLoS ONE. 2012;7(4):e35797. https://doi.org/10.1371/journ al.pone.0035797.

12. Yu ITS, Li Y, Wong TQ, et al. Evidence of airborne transmission of the severe acute respiratory syndrome virus. N Engl J Med. 2004;350:1731-9.

13. Zou L, Ruan F, Huang M, Liang L, Huang H, Hong Z, Yu J, Kang M, Song Y, Xia J, Guo Q, Song T, He J, Yen HL, Peiris M, Wu J. SARS-CoV-2 viral load in upper respiratory specimens of infected patients. N Engl J Med. 2020;382(12):1177-9. https:// doi.org/10.1056/NEJMc2001737.

14. Cook TM. Personal protective equipment during the coronavirus disease (COVID) 2019 pandemic - a narrative review. Anaesthesia. 2019. https://doi.org/10.1111/anae.15071.

15. Ong SWX, Tan YK, Chia PY, Lee TH, Ng OT, Wong MSY, et al. Air, surface environmental, and personal protective equipment contamination by severe acute respiratory syndrome coronavirus 2 (SARS-CoV-2) from a symptomatic patient. JAMA. 2020. https ://doi.org/10.1001/jama.2020.3227.

16. World Health Organization. Rational use of protective equipment for Corona Visur disease 2019 (COVID-19). https://apps.who.int/ iris/bitstream/handle/10665/331215/WHO-2019-nCov-IPCPPE use-2020.1-eng.pdf.

17. Geneid A, Nawka T, Schindler A, Oguz H, Chrobok V, Calcinoni O, Zehnhoff-Dinnesen A, Neumann K, Farahat M, Abou-Elsaad
T, Moerman M, Chavez E, Fishman J, Yazaki R, Arnold B, Frajkova Z, Graf S, Pflug C, Drsata J, Desuter G, Samuelsson C, Tedla M, Costello D, Sjögren E, Hess M, Kinnari T, Rubin J. Union of the European Phoniatricians' position statement on the exit strategy of phoniatric and laryngological services: staying safe and getting back to normal after the peak of coronavirus disease 2019 (issued on 25th May 2020). J LaryngolOtol. 2020. https:// doi.org/10.1017/S002221512000122X.

18. Kimura Y, Ueha R, Furukawa T, Oshima F, Fujitani J, Nakajima J, Kaneoka A, Aoyama H, Fujimoto Y, Umezaki T. Society of swallowing and dysphagia of Japan: position statement on dysphagia management during the COVID-19 outbreak. Auris Nasus Larynx. 2020. https://doi.org/10.1016/j.anl.2020.07.009.

19. Soldatova L, Williams C, Postma GN, Falk GW, Mirza N. Virtual dysphagia evaluation: practical guidelines for dysphagia management in the context of the COVID-19 pandemic. Otolaryngol Head Neck Surg. 2020;163(3):455-8.

20. Fritz MA, Howell RJ, Brodsky MB, Suiter DM, Dhar SI, Rameau A, Richard T, Skelley M, Ashford JR, O'Rourke AK, Kuhn MA. Moving forward with dysphagia care: implementing strategies during the COVID-19 pandemic and beyond. Dysphagia. 2020. https://doi.org/10.1007/s00455-020-10144-9.

21. Miles A, Connor NP, Varindani Desai R, Jadcherla S, Allen J, Brodsky MB, Garand KL, Malandraki GA, McCulloch TM, Moss M, Murray J, Pulia M, Riquelme LF, Langmore SE. Dysphagia care across the continuum: a multidisciplinary Dysphagia Research Society Taskforce report of service-delivery during the COVID-19 global pandemic. Dysphagia. 2020. https://doi. org/10.1007/s00455-020-10153-8.

Publisher's Note Springer Nature remains neutral with regard to jurisdictional claims in published maps and institutional affiliations.

\section{Antonio Schindler MD}

Laura W.J. Baijens $\mathrm{MD}, \mathrm{PhD}$

Pere Clave MD, PhD

Bjorn Degen SLP

Stephanie Duchac SLP

Rainer Dziewas MD, PhD

Daniele Farneti MD

Shaheen Hamdy $\mathrm{MD}, \mathrm{PhD}$

Emilia Michou SLP, PhD

Peter Pokieser MD

Renee Speyer SLP, PhD

Margaret Walshe $\mathrm{MD}, \mathrm{PhD}$

Eric Verin $\mathrm{MD}, \mathrm{PhD}$

Nathalie Rommel SLP, PhD 